Article

\title{
Temperature-Insensitive Imaging Properties of a Broadband Terahertz Nonlinear Quantum Cascade Laser
}

\author{
Atsushi Nakanishi *(D), Shohei Hayashi, Hiroshi Satozono ${ }^{(D)}$ and Kazuue Fujita * (D) \\ Central Research Laboratory, Hamamatsu Photonics K. K., 5000 Hirakuchi, Hamakita, Hamamatsu City, \\ Shizuoka 434-8601, Japan; shohei.hayashi@crl.hpk.co.jp (S.H.); satozono@crl.hpk.co.jp (H.S.) \\ * Correspondence: nakanishi@crl.hpk.co.jp (A.N.); kfujita@crl.hpk.co.jp (K.F.)
}

Received: 21 July 2020; Accepted: 25 August 2020; Published: 27 August 2020

check for updates

\begin{abstract}
Terahertz (THz) quantum cascade laser sources based on optical nonlinearity are the only electrically pumped monolithic semiconductor sources operable at room temperature in the $0.6-6 \mathrm{THz}$ range. We investigated the temperature dependence of the imaging characteristics of a broadband $\mathrm{THz}$ nonlinear quantum cascade laser and evaluated several important properties: the spectrum, far-field pattern and THz imaging results. Consequently, we found that the far-field patterns were single-lobed Gaussian-like, and THz images were well-resolved despite the lower operating temperature of the device. The stable temperature-performance indicates that this broadband $\mathrm{THz}$ source is promising for $\mathrm{THz}$ imaging applications.
\end{abstract}

Keywords: terahertz; quantum cascade laser; nonlinear optics; imaging

\section{Introduction}

Terahertz $(\mathrm{THz})$ frequency range radiation $(0.3-10 \mathrm{THz})$ has been used to demonstrate the imaging of objects that are opaque at optical frequencies [1,2]. There are many $\mathrm{THz}$ applications, including the screening of chemical substances [3-5], and nondestructive imaging for industrial materials [6-10] and historical arts objects [11,12]. THz quantum cascade lasers (THz-QCLs) are the most promising light source in the $\mathrm{THz}$ region $[13,14]$, and many studies on $\mathrm{THz}$ imaging technology have been performed using THz-QCLs [15].

Alongside the development of THz-QCL technology, THz-QCL sources based on intra-cavity difference-frequency generation (DFG) have been developed as a new type of room temperature semiconductor $\mathrm{THz}$ light source [16]. These devices, known as THz DFG-QCLs or THz NL-QCLs ( $\mathrm{THz}$ nonlinear quantum cascade lasers), use two-color mid-IR laser active regions engineered to exhibit a large intersubband nonlinear susceptibility $\chi^{2}$ for an efficient THz DFG process. Currently, THz NL-QCLs based on the InGaAs/InAlAs/InP material system are the only electrically pumped monolithic $\mathrm{THz}$ semiconductor sources operable at room temperature in the $0.6 \mathrm{THz}$ to $6 \mathrm{THz}$ range [17-20]. Since 2012, the performance of THz NL-QCLs has been improved by adopting a Cherenkov emission scheme [21]. In addition, recent efforts in wavefunction engineering using a dual-upper-state (DAU) active region [22,23] possessing a broad gain bandwidth led to a significant improvement in terms of device performance, as well as the higher optical nonlinearity of the active region for efficient terahertz generation. In fact, without the integration of two $\mathrm{QCL}$ active regions for the dual-wavelength emission, THz generation is achieved in mid-infrared QCLs, based on a DAU active region with a device structure almost identical to commercialized, typical mid-infrared QCLs $[24,25]$. As a result of the enhanced optical nonlinearity, this approach has expanded the lower limit of the frequency range down to $615 \mathrm{GHz}$ [20]. This is the first demonstration of a sub-terahertz QCL source without an external magnetic field [19]. 
In addition to the features that THz NL-QCLs are compact, room temperature semiconductor light sources, these devices show a single-lobed Gaussian-like beam pattern due to the Cherenkov emission scheme $[21,26]$. Such good beam quality has major advantages in terms of practical applications. Furthermore, their THz emission spectra, associated with the mid-IR pumps used in the devices, can be exploited to achieve ultra-broadband bandwidth, as well as single-mode operation, with various device configurations. Therefore, THz NL-QCLs are suitable for imaging applications, and in fact, we previously demonstrated high-quality non-destructive imaging using a broadband THz NL-QCL [26]. Although THz NL-QCLs are operable at room temperature, the output power can be increased by decreasing the operating temperature; this is attributed to the enhancement of the mid-IR pump power from QCLs, which strongly depends on the operating temperature [24] in general. Accordingly, cooling is also useful when requiring higher THz output power for specific imaging applications. However, both the emission frequency and output direction of the $\mathrm{THz}$ radiation from $\mathrm{THz}$ NL-QCLs may be influenced by changing the operating temperature. In this work, we investigated the temperature dependence of the imaging properties (far-field pattern and THz imaging results) of a broadband THz NL-QCL.

\section{Methods}

A broadband THz NL-QCL with a distributed feedback (DFB)/Fabry Perot (FP) configuration operating in pulsed mode was used for the $\mathrm{THz}$ imaging experiment; details of the device structure are described in ref. 23. Figure 1a shows the THz spectra of a $14 \mu \mathrm{m}$-wide, $3 \mathrm{~mm}$-long device, collected at different temperatures. As shown in the figure, the device exhibited a small temperature dependence, and the $\mathrm{THz}$ emission bandwidth remained constant over the whole temperature range. The broadband emission spectra extended from $1.2 \mathrm{THz}$ to $3.0 \mathrm{THz}$, covering more than one octave at room temperature, which is a consequence of the nonlinear mixing between distributed-feedback single-mode lasing and multi-mode emission, due to the use of an FP cavity.

Figure $1 \mathrm{~b}$ depicts the temperature dependence of the $\mathrm{THz}$ current-output (I-L) characteristics in the temperature range of $160-297 \mathrm{~K}$, and the inset shows plots of the output power at a current of $1.7 \mathrm{~A}$ as a function of temperature. The device showed a THz peak output power of approximately $275 \mu \mathrm{W}$ at $160 \mathrm{~K}$, and approximately $80 \mu \mathrm{W}$ at $297 \mathrm{~K}$. The higher THz output power at low temperatures is attributed to the increased mid-IR pump power. On the other hand, the measured THz output powers were smaller than those in our previous report; this is mainly due to the shift of the center frequency of the broadband $\mathrm{THz}$ spectrum of the device. In general, the $\mathrm{THz}$ output power due to DFG is proportional to the square of the $\mathrm{THz}$ frequency and the optical nonlinearity.

We obtained $\mathrm{THz}$ imaging with a transmission imaging system [26]. Figure 2 depicts the experimental setup of our imaging system. The $\mathrm{THz}$ beam from our device was collimated with an off-axis parabolic (OAP) mirror $(f=50 \mathrm{~mm})$ and was focused onto a test object by using an aspheric plastic lens ( $f=40 \mathrm{~mm}$; Tsurupica ${ }^{\circledR}$, Pax Co., Sendai, Japan). Then, the THz beam transmitted through the object was collimated using another aspheric lens (Tsurupica ${ }^{\circledR}, f=40 \mathrm{~mm}$ ) and was collected on the Golay cell detector using another off-axis parabolic mirror $(f=100 \mathrm{~mm})$. Terahertz images were acquired by the raster-scanning method. The object was mounted on a computer-controlled two-axis translation stage. To obtain spectroscopic images at a specific frequency, we placed the bandpass filter of that frequency in front of the detector. At the focal point, the $\mathrm{THz}$ beam diameter was about $0.5-0.6 \mathrm{~mm}$. 

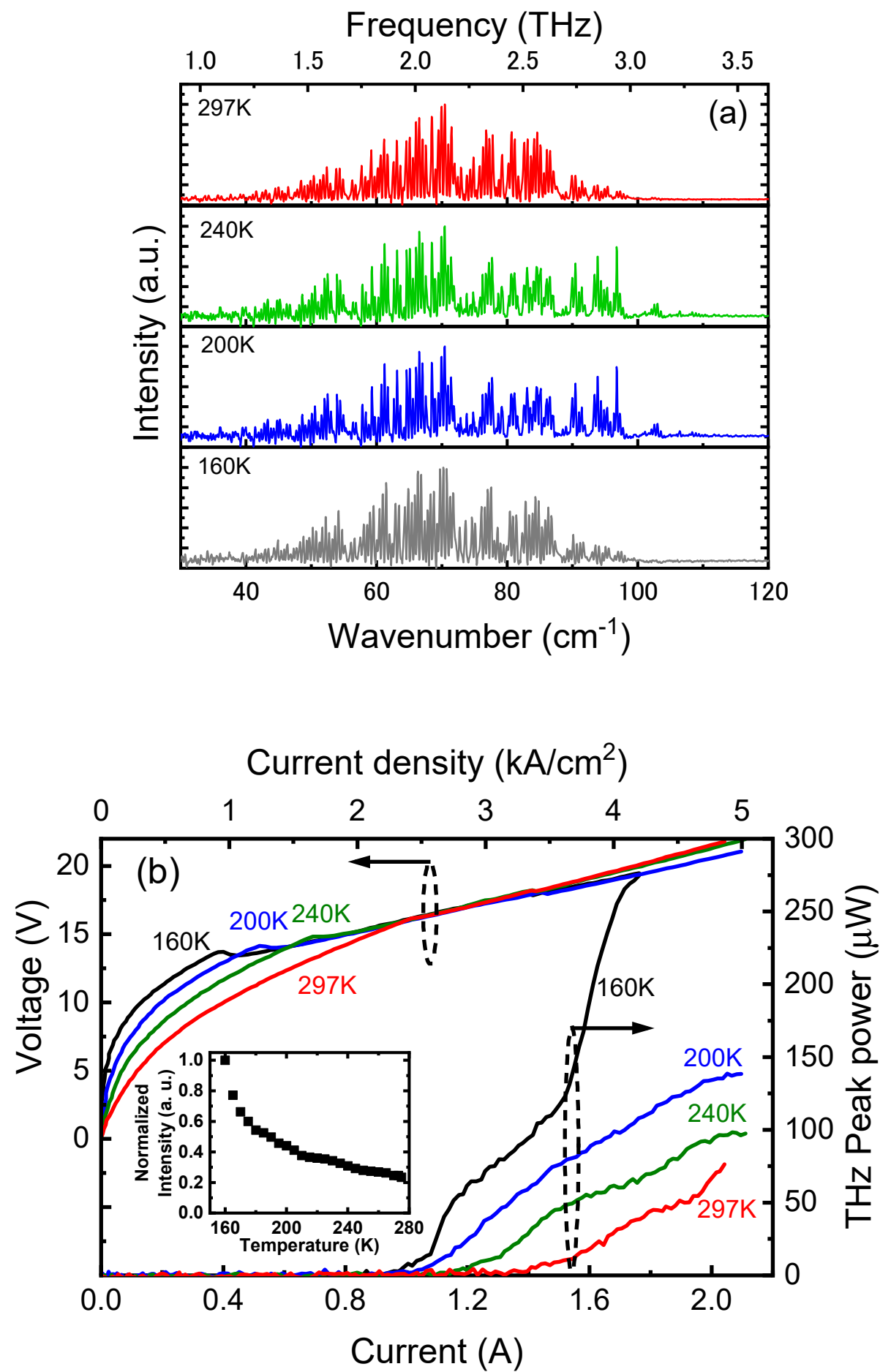

Figure 1. (a) Spectra of the THz NL-QCL (terahertz nonlinear quantum cascade laser): at $297 \mathrm{~K}, 240 \mathrm{~K}$, $200 \mathrm{~K}$ and $160 \mathrm{~K}$. (b) Current-voltage-THz-light-output characteristic of the THz NL-QCL at different temperatures, measured in pulsed mode. Inset shows normalized output intensity of THz NL-QCL as a function of temperature. 


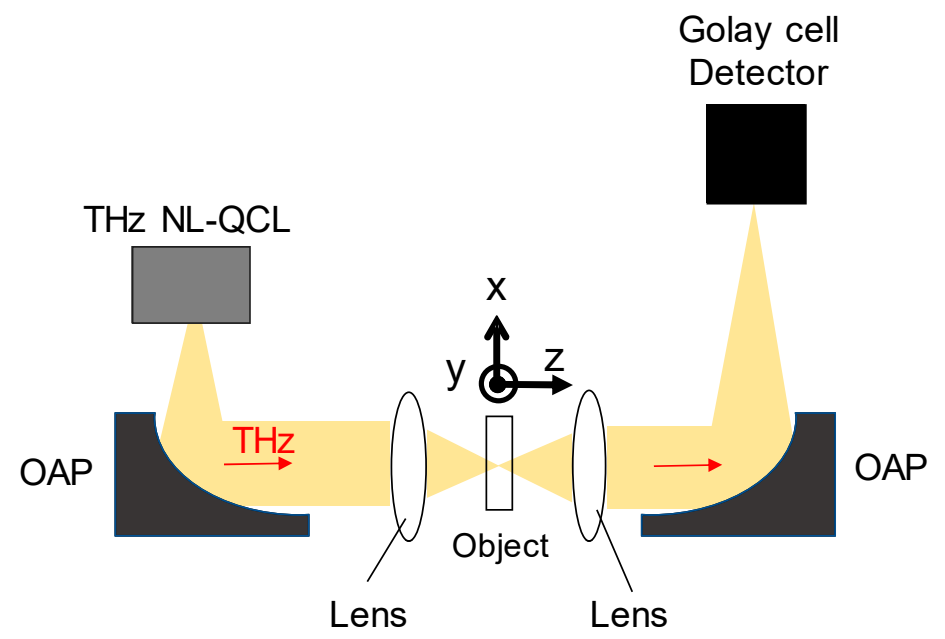

Figure 2. THz transmission imaging system.

\section{Results and Discussion}

Figure 3a-d show the THz beam patterns from our THz NL-QCL at temperatures ranging from $297 \mathrm{~K}$ to $160 \mathrm{~K}$. To map the 2D far-field emission patterns of the devices, we used a set-up consisting of two motorized XY translation stages [26]. As shown in Figure 3a-d, the THz beam patterns at each temperature showed Gaussian-like shapes that are favorable for $\mathrm{THz}$ imaging applications. Figure $4 \mathrm{a}-\mathrm{d}$ depict the line profiles extracted from Figure $3 \mathrm{a}-\mathrm{d}$ along the horizontal broken lines corresponding to the fast axis. Figure $4 \mathrm{e}-\mathrm{h}$ depict the line profiles extracted from Figure $3 \mathrm{a}-\mathrm{d}$ along the vertical broken lines corresponding to the slow axis. From the horizontal and vertical profiles, the beam full-width at half-maximum (FWHM) values were $17.9 \mathrm{~mm}, 17.7 \mathrm{~mm}, 18.7 \mathrm{~mm}$ and $18.8 \mathrm{~mm}$ along the fast axis (Figure 4a-d, respectively), and similarly $21.9 \mathrm{~mm}, 22.4 \mathrm{~mm}, 22.9 \mathrm{~mm}$ and $23.5 \mathrm{~mm}$ along the slow axis (Figure $4 \mathrm{e}-\mathrm{h}$, respectively), for which the corresponding divergence angles were estimated to be $17.3^{\circ}$, $17.1^{\circ}, 18.0^{\circ}$ and $18.1^{\circ}$ for the fast axis, and $21.0^{\circ}, 21.5^{\circ}, 22.0^{\circ}$ and $22.5^{\circ}$ for the slow axis, respectively. We found that both the output direction of the $\mathrm{THz}$ beam and the divergence angle were insensitive to the operating temperature.
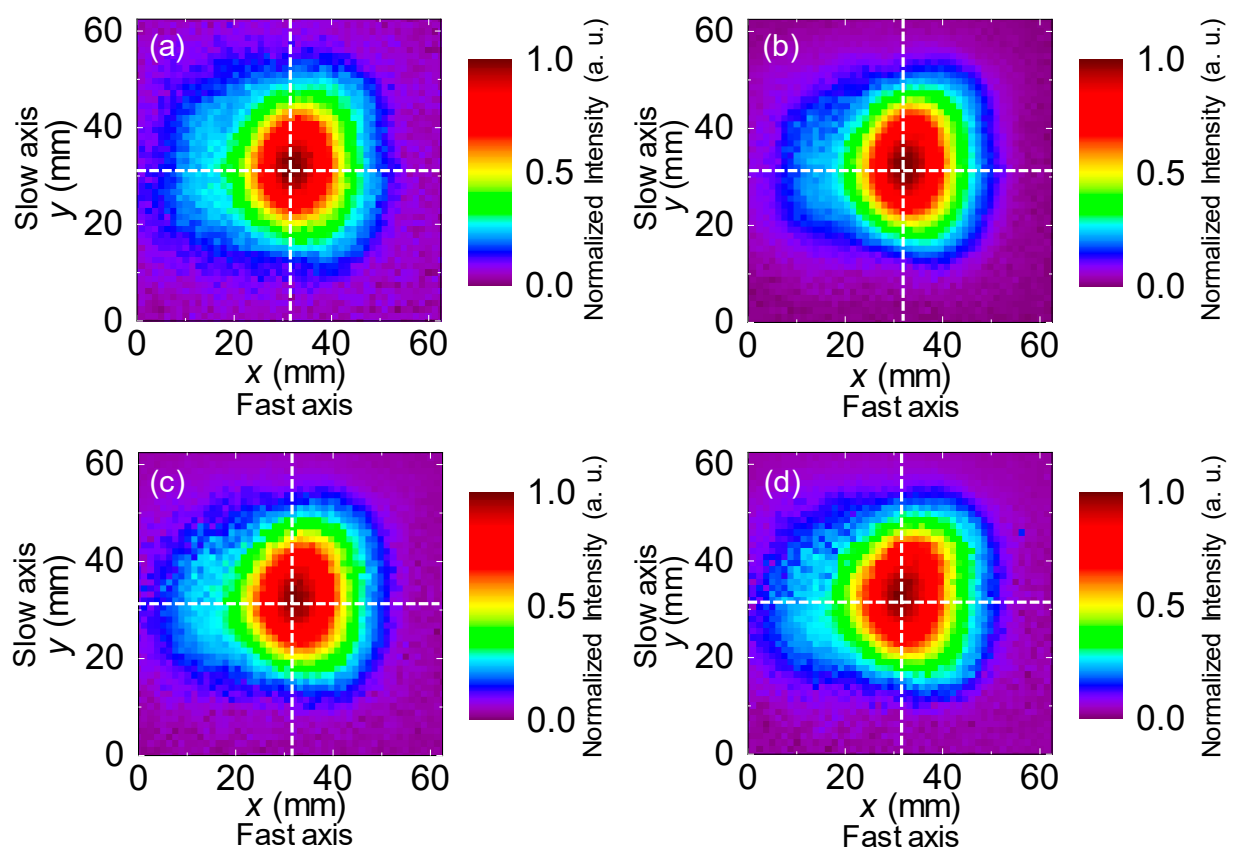

Figure 3. Far-field profiles from THz NL-QCL at: (a) 297 K, (b) $240 \mathrm{~K}$, (c) $200 \mathrm{~K}$ and (d) $160 \mathrm{~K}$. 

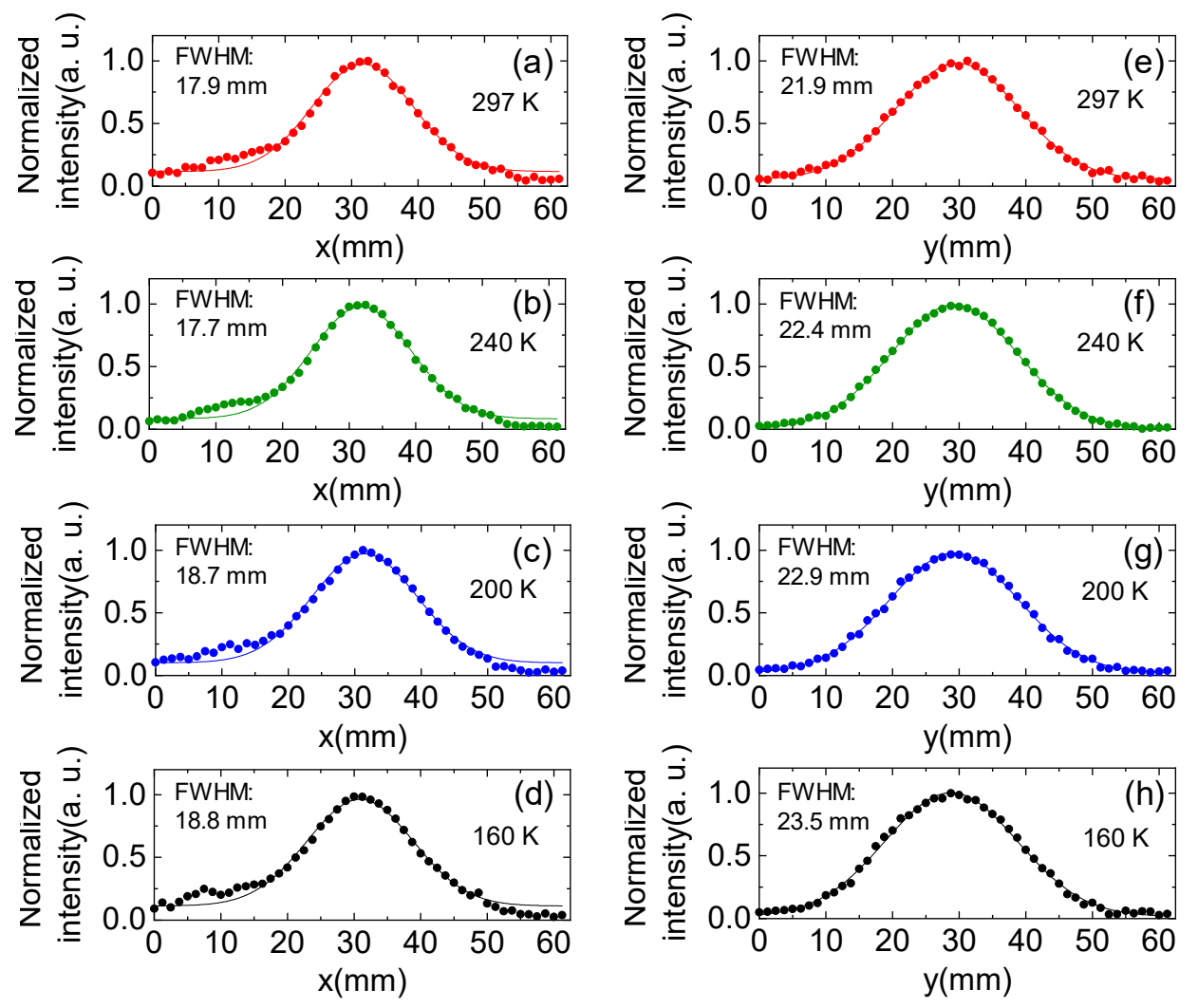

Figure 4. Horizontal sections of the beam profiles at: (a) $297 \mathrm{~K}$, (b) $240 \mathrm{~K}$, (c) $200 \mathrm{~K}$ and (d) $160 \mathrm{~K}$. Vertical sections of the beam profiles at: (e) $297 \mathrm{~K}$, (f) $240 \mathrm{~K}$, (g) $200 \mathrm{~K}$ and (h) $160 \mathrm{~K}$.

Figure 5a shows a photograph of a stainless-steel test object, whose thickness was $0.3 \mathrm{~mm}$. As shown in Figure $5 \mathrm{a}$, the test object had $0.5 \mathrm{~mm}$-wide stripes. We obtained $\mathrm{THz}$ images of the test object with the THz NL-QCL $(100 \times 180$ pixels, $0.2 \mathrm{~mm}$ steps $)$. Figure $5 \mathrm{~b}-\mathrm{d}$ show THz images of the test object obtained by the imaging system equipped with the THz NL-QCL, in which the QCL device was operated at $240 \mathrm{~K}, 200 \mathrm{~K}$ and $160 \mathrm{~K}$ (Figure $5 \mathrm{~b}-\mathrm{d}$, respectively). We found that the $\mathrm{THz}$ images were well-resolved despite the changing operating temperature. For further investigation, we acquired line profiles of the terahertz intensity along the horizontal axis and vertical axis from Figure $5 \mathrm{~b}-\mathrm{d}$. In a previous work, the results of the modulation depth of the test object (line pair pattern having $0.5 \mathrm{~mm}$-wide stripes) were over $20 \%$. According to the $20 \%$ modulation threshold criterion, the spatial resolution was better than $0.5 \mathrm{~mm}$ [26]. Therefore, we evaluated imaging quality using a profile of stripe of $0.5 \mathrm{~mm}$. Figure 6 illustrates the method of extracting line profiles from the $\mathrm{THz}$ images. As shown in Figure 6, we highlighted two areas including $3 \times 21$ pixels $\left(X_{i j}\right.$ and $Y_{i j}, i=1,2$, $3, j=1,2, \ldots, 21)$. From the pixels, we could obtain three profiles corresponding to three groups of $1 \times 21$ pixels along the horizontal direction $\left(X_{1,1}-X_{2,21}, X_{2,1}-X_{2,21}\right.$ and $\left.X_{3,1}-X_{3,21}\right)$. Then, we obtained three profiles corresponding to three groups of $1 \times 21$ pixels along the vertical direction $\left(Y_{1,1}-Y_{2,21}\right.$, $Y_{2,1}-Y_{2,21}$ and $\left.Y_{3,1}-Y_{3,21}\right)$. From three profiles along the horizontal direction and vertical direction, we calculated the average line profile and standard deviation for the horizontal direction and vertical direction. Figure $7 \mathrm{a}-\mathrm{f}$ shows line profiles of $\mathrm{THz}$ images for the horizontal direction and vertical direction obtained with the THz NL-QCL at $240 \mathrm{~K}, 200 \mathrm{~K}$ and $160 \mathrm{~K}$, respectively. The insets show the profiles of the non-normalized intensity without error-bars: $X_{2,1}-X_{2,21}$ and $Y_{2,1}-Y_{2,21}$. These profiles were almost consistent with each other despite the changing operating temperature. This is attributable to the temperature-insensitivity of the imaging properties; that is, both the output direction and divergence angle of the beam were not influenced by the operating temperature. In Figure 7, the error bars became smaller with decreasing temperature, since a higher signal-to-noise ratio (SNR) due to 
the higher $\mathrm{THz}$ output power was obtained at a lower temperature. There was a trade-off between operating temperature and the SNR.
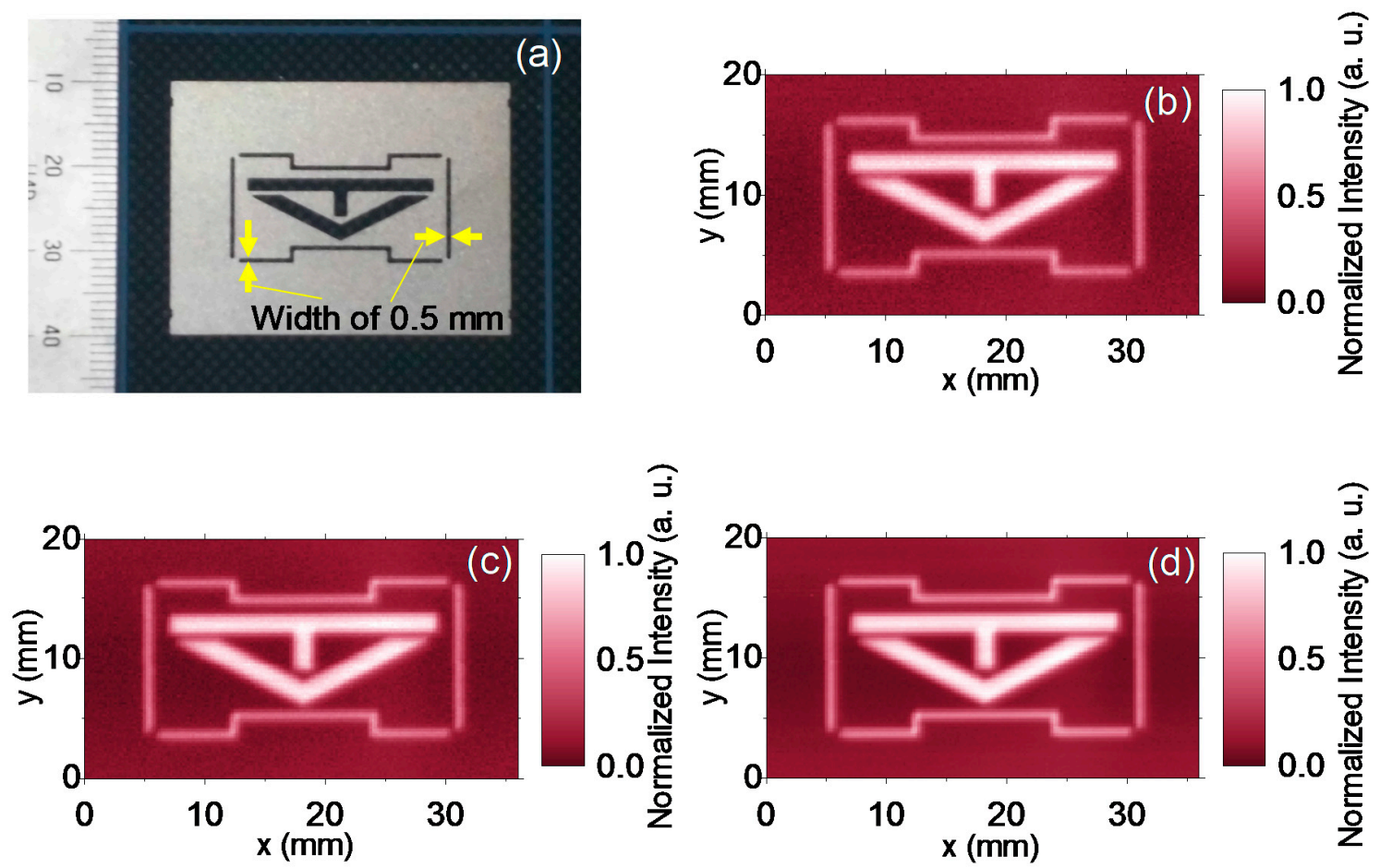

Figure 5. (a) Photograph of test object whose thickness was $0.3 \mathrm{~mm}$. THz images of the test object obtained by THz NL-QCL at (b) $240 \mathrm{~K}$, (c) $200 \mathrm{~K}$ and (d) $160 \mathrm{~K}$.

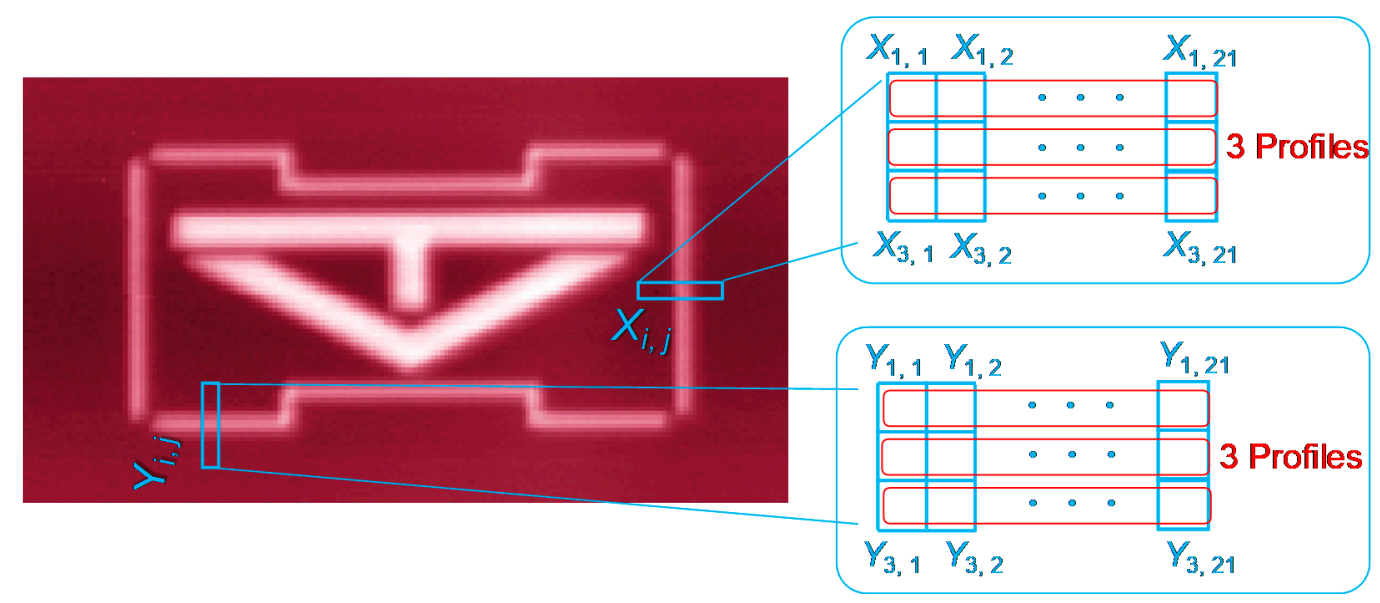

Figure 6. Schematic illustration of extraction of vertical and horizontal profiles from $\mathrm{THz}$ image. 

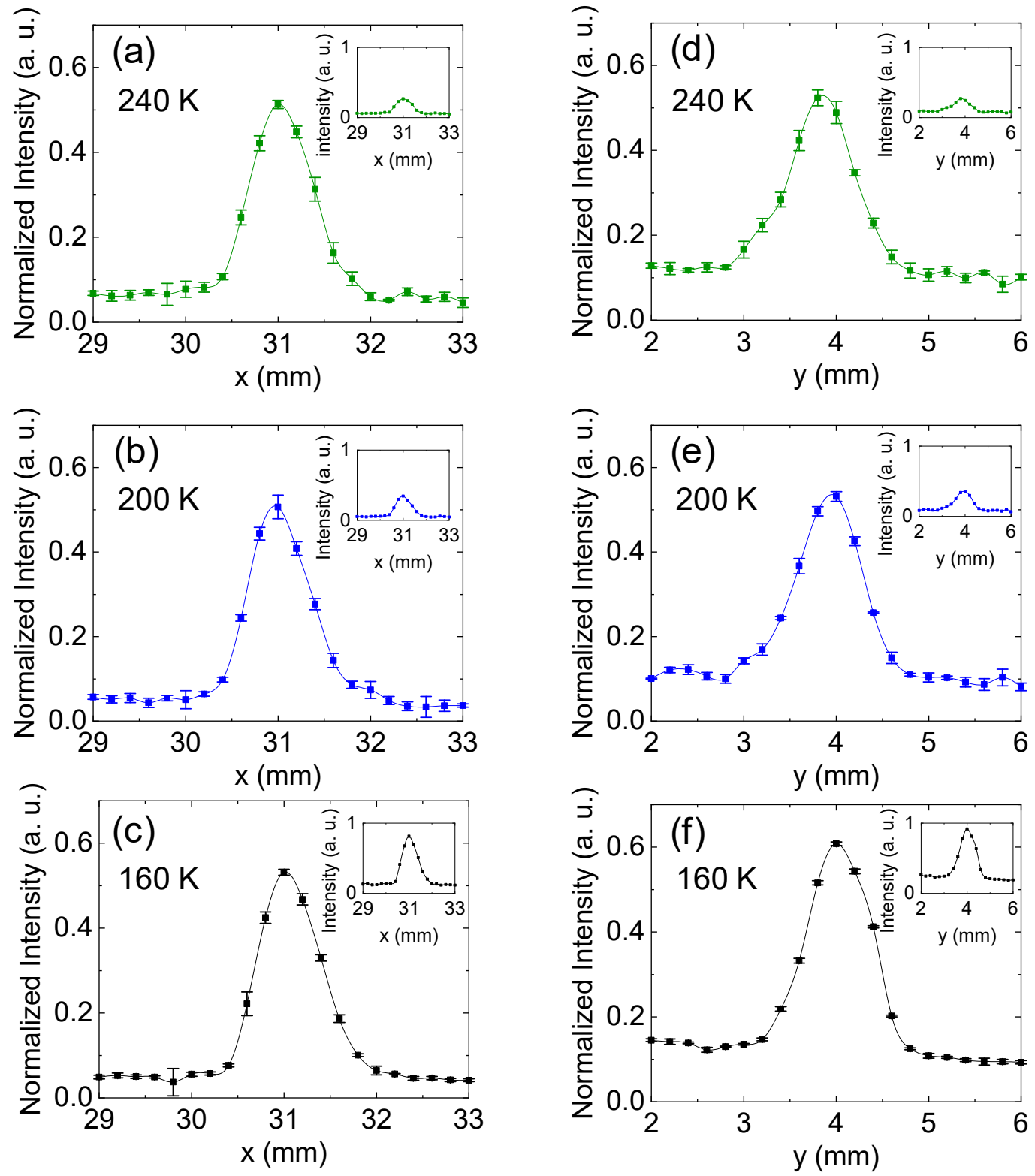

Figure 7. Line profiles of normalized THz intensity along horizontal direction at: (a) $240 \mathrm{~K}$, (b) $200 \mathrm{~K}$ and (c) $160 \mathrm{~K}$. Line profiles of normalized THz intensity along vertical direction at: (d) $240 \mathrm{~K},(\mathbf{e}) 200 \mathrm{~K}$ and (f) $160 \mathrm{~K}$. Insets show profiles of non-normalized intensity.

\section{Conclusions}

In conclusion, we investigated the temperature dependence of the imaging properties of a broadband THz NL-QCL. We found that the spectrum, the far-field pattern and the THz imaging results were constant despite the decreasing temperature of the THz NL-QCL. In future work, we plan to demonstrate 3D imaging, spectroscopic imaging and real-time imaging using THz NL-QCLs, and for that work, the temperature-independent properties demonstrated in this paper will be very useful.

Author Contributions: Data curation, A.N. and S.H.; Formal analysis, A.N. and S.H.; Investigation, A.N.; Project administration, K.F.; Writing—original draft, A.N.; Writing—review \& editing, A.N., H.S. and K.F. All authors have read and agreed to the published version of the manuscript.

Funding: This research and development work was supported by MIC/SCOPE \#195006001. 
Acknowledgments: The authors express their gratitude to A. Ito for sample preparation and device fabrication, and to K. Kuroyanagi for technical support in the THz measurements. The authors also wish to acknowledge T. Edamura for his valuable comments.

Conflicts of Interest: The authors declare no conflict of interest.

\section{References}

1. Tonouchi, M. Cutting-edge terahertz technology. Nat. Photonics 2007, 1, 97. [CrossRef]

2. Dhillon, S.S.; Vitiello, M.S.; Linfield, E.H.; Davies, A.G.; Hoffmann, M.C.; Booske, J.; Paoloni, C.; Gensch, M.; Weightman, P.; Williams, G.P.; et al. The 2017 terahertz science and technology roadmap. J. Phys. D Appl. Phys. 2017, 50, 043001. [CrossRef]

3. Kawase, K.; Ogawa, Y.; Watanabe, Y. Non-destructive terahertz imaging of illicit drugs using spectral fingerprints. Opt. Express 2003, 11, 2549-2554. [CrossRef]

4. Murate, K.; Kawase, K. Perspective: Terahertz wave parametric generator and its applications. J. Appl. Phys. 2018, 124, 160901. [CrossRef]

5. Kato, M.; Tripathi, S.R.; Murate, K.; Imayama, K.; Kawase, K. Non-destructive drug inspection in covering materials using a terahertz spectral imaging system with injection-seeded terahertz parametric generation and detection. Opt. Express 2016, 24, 6425-6432. [CrossRef]

6. Busch, S.; Probst, T.; Schwerdtfeger, M.; Dietz, R.; Palaci, J.; Koch, M. Terahertz transceiver concept. Opt. Express 2014, 22, 16841-16846. [CrossRef]

7. Okano, M.; Watanabe, S. Anisotropic optical response of optically opaque elastomers with conductive fillers as revealed by terahertz polarization spectroscopy. Sci. Rep. 2016, 6, 39079. [CrossRef]

8. Watanabe, S. Terahertz Polarization Imaging and Its Applications. Photonics 2018, 5, 58. [CrossRef]

9. Okano, M.; Watanabe, S. Internal Status of Visibly Opaque Black Rubbers Investigated by Terahertz Polarization Spectroscopy: Fundamentals and Applications. Polymers 2018, 11, 9. [CrossRef]

10. Okano, M.; Watanabe, S. Inspection of internal filler alignment in visibly opaque carbon-black-rubber composites by terahertz polarization spectroscopy in reflection mode. Polym. Test. 2018, 72, 196-201. [CrossRef]

11. Dandolo, C.L.K.; Guillet, J.P.; Ma, X.; Fauquet, F.; Roux, M.; Mounaix, P. Terahertz frequency modulated continuous wave imaging advanced data processing for art painting analysis. Opt. Express 2018, 26, 5358-5367. [CrossRef] [PubMed]

12. Dandolo, C.L.K.; Lopez, M.; Fukunaga, K.; Ueno, Y.; Pillay, R.; Giovannacci, D.; Du, Y.L.; Bai, X.; Menu, M.; Detalle, V. Toward a multimodal fusion of layered cultural object images: Complementarity of optical coherence tomography and terahertz time-domain imaging in the heritage field. Appl. Opt. 2019, 58, 1281-1290. [CrossRef] [PubMed]

13. Köhler, R.; Tredicucci, A.; Beltram, F.; Beere, H.E.; Linfield, E.H.; Davies, A.G.; Ritchie, D.A.; Iotti, R.C.; Rossi, F. Terahertz semiconductor heterostructure laser. Nature 2002, 417, 156. [CrossRef] [PubMed]

14. Williams, B.S. Terahertz quantum-cascade lasers. Nat. Photonics 2007, 1, 517. [CrossRef]

15. Locatelli, M.; Ravaro, M.; Bartalini, S.; Consolino, L.; Vitiello, M.S.; Cicchi, R.; Pavone, F.; De Natale, P. Real-time terahertz digital holography with a quantum cascade laser. Sci. Rep. 2015, 5, 13566. [CrossRef] [PubMed]

16. Belkin, M.A.; Capasso, F.; Belyanin, A.; Sivco, D.L.; Cho, A.Y.; Oakley, D.C.; Vineis, C.J.; Turner, G.W. Terahertz quantum-cascade-laser source based on intracavity difference-frequency generation. Nat. Photonics 2007, 1, 288-292. [CrossRef]

17. Belkin, M.A.; Capasso, F. New frontiers in quantum cascade lasers: High performance room temperature terahertz sources. Phys. Scr. 2015, 90, 118002. [CrossRef]

18. Lu, Q.; Razeghi, M. Recent Advances in Room Temperature, High-Power Terahertz Quantum Cascade Laser Sources Based on Difference-Frequency Generation. Photonics 2016, 3, 42. [CrossRef]

19. Fujita, K.; Jung, S.; Jiang, Y.; Kim, J.H.; Nakanishi, A.; Ito, A.; Hitaka, M.; Edamura, T.; Belkin, M.A. Recent progress in terahertz difference-frequency quantum cascade laser sources. Nanophotonics 2018, 7, 1795-1817. [CrossRef]

20. Fujita, K.; Hayashi, S.; Ito, A.; Hitaka, M.; Dougakiuchi, T. Sub-terahertz and terahertz generation in long-wavelength quantum cascade lasers. Nanophotonics 2019, 8, 2235-2241. [CrossRef] 
21. Vijayraghavan, K.; Adams, R.W.; Vizbaras, A.; Jang, M.; Grasse, C.; Boehm, G.; Amann, M.C.; Belkin, M.A. Terahertz sources based on Čerenkov difference-frequency generation in quantum cascade lasers. Appl. Phys. Lett. 2012, 100, 251104. [CrossRef]

22. Fujita, K.; Edamura, T.; Furuta, S.; Yamanishi, M. High-performance, homogeneous broad-gain quantum cascade lasers based on dual-upper-state design. Appl. Phys. Lett. 2010, 96, 241107. [CrossRef]

23. Fujita, K.; Hitaka, M.; Ito, A.; Edamura, T.; Yamanishi, M.; Jung, S.; Belkin, M.A. Terahertz generation in mid-infrared quantum cascade lasers with a dual-upper-state active region. Appl. Phys. Lett. 2015, 106, 251104. [CrossRef]

24. Fujita, K.; Hitaka, M.; Ito, A.; Yamanishi, M.; Dougakiuchi, T.; Edamura, T. Ultra-broadband room temperature terahertz quantum cascade laser sources based on difference frequency generation. Opt. Express 2016, 24, 16357-16365. [CrossRef] [PubMed]

25. Fujita, K.; Ito, A.; Hitaka, M.; Dougakiuchi, T.; Edamura, T. Low-threshold room temperature continuous-wave operation of a terahertz difference-frequency quantum cascade laser source. Appl. Phys. Express 2017, 10, 082102. [CrossRef]

26. Nakanishi, A.; Fujita, K.; Horita, K.; Takahashi, H. Terahertz imaging with room temperature terahertz difference-frequency quantum-cascade laser sources. Opt. Express 2019, 27, 1884-1893. [CrossRef] [PubMed]

(C) 2020 by the authors. Licensee MDPI, Basel, Switzerland. This article is an open access article distributed under the terms and conditions of the Creative Commons Attribution (CC BY) license (http://creativecommons.org/licenses/by/4.0/). 